\title{
Disambiguation by Information Structure in DRT
}

\author{
Kurt Eberle * \\ Institut für Maschinelle Sprachverarbeitung \\ Universität Stuttgart \\ Azenbergstr. 12 \\ D-70174 Stuttgart
}

\begin{abstract}
'Text understanding and high quality machine translation often necessitate the disambiguation of ambigous structures or lexical elements. Drawing inferences from the context can be a means for resolving semantic ambiguities. However, often, this is an expensive strategy that, in addition, not always comes up with a clear preference for one of the alternatives. In this paper, we argue that in a number of cases deep semantic analyses can be avoided by taking into account the constraints that the alternative readings impose onto the information structure. To this end, we present a study of the ambigous German adverb erst and point out the particular circumstances under which the given information structure disambiguates the adverb without further semantic analysis.
\end{abstract}

\section{Introduction}

German erst is ambigous. Consider the following examples:

(1) Peter zeigte erst auf die vierte Glückszahl.

a) Und dann auf die zweite.

(Peter first pointed to the fourth lucky number. And then to the second.)

b) Nicht zuvor auf die erste, zweite oder dritte. (Peter only pointed to the fourth lucky number. Not to the first, second or third.)

c) Noch nicht auf die fünfte.

(Peter only pointed to the fourth lucky number so far. Not yet to the fifth.)

The alternative contexts a) - c) determine the meaning of the first sentence of (1) according to

\footnotetext{
${ }^{*}$ This paper describes research done within the Sonderforschunsbereich 340 at IMS. I would like to thank Anette Frank, Hans Kamp, Michael Schiehlen and the other members of the IMS semantics group for helpfull discussion.
}

the disambiguating translations presented. The example testifies the following three uses of erst:

- In the context (1.a), the recipient understands the introduced event as the first of a sequence of events that he expects to be completed by the following text. We call this reading:

the First of a Sequence-reading (FS).

- In the context (1.b), the recipient understands erst as a signal of the speaker/writer that the occurrence of the reported event is not preceded by the occurrence of similar (alternative) events. We call this reading: the Exclusion of Preceding Alternativesreading (EPA).

- In the context (1.c), the recipient understands the event as element of a sequence of events, and the realization of the sequence, in particular the reported realization of the event at the textual perspective time, seerns to be in retardation, with regard to some (previous) expectation about the realization dates of the sequence. We call this reading: the Retardation-reading ( $R$ )

As can be seen from the example, the contextual disambiguation not only is needed for understanding the text, but is a prerequisite for high quality translation.

In the literature, different formalizations have been discussed ((Kön79), (Löb89), (Kön91), (HR81) (the latter one for the similar noch and schon) and others). With respect to the focus adverb use (the cases (1.b) and (1.c); (1.a) being an example of the temporal adverb use), modellings are prevailing that associatc erst with different scales (cf. (Löb89)). However, a precise evaluation of the context that can decide about the relevant reading (for instance, what information defines which scale) is still missing. We tackle this problem in the framework of Discourse Representation 'Theory (DRT) (Kam81), assuming that discourse representations (DRSs) may be augmented by information structure. 


\section{The erst-readings, their entailments, presuppositions and implicatures}

\subsection{The first of a Sequence interpretation}

In this paper, we cannot go into detail with tests that partition the meaning of a sontence into presuppositions, asscrtions proper and implicatures the recipient is allowed to draw from the sentence (cf. (Lev83) for an overview of the notions used, the tests associated with them and the problems connected to them). We directly como np with the DRss that, to our opinion, represent the intpact of the different readings. Wo begin with the FS-reading of (1):

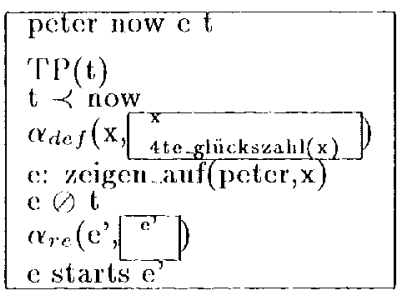

IIcre, 'l'P stands for the actual (past) temporal perspective that holds for the given utterance/text situation. With respect to the representation and resolution of presuppositions in D R' $L$, we relate to (vdS92). We slightly deviate from the approach suggested there, however, in that we use a notation for the presupposition triggers that is akin to the suggestion of (BFS+ 94): we use so-called $\alpha$-conditions which describe the presupposed objects and their characterization. In our framework $\alpha-$ conditions subsume different types of projection problems. 'The type is characterized by the $\alpha$-index ( $p r e s p$ stands for 'classical' presuppositions, def for definite descriptions, $r t$ for refcrence time, re for reference event etc., compare (1.be95) for an overview). This index triggers the projection routine that is specific to the respeclive resolution problent. 'The first argument of the condition schema highlights the distinguished discourse referent. (DRF) of the structure to be projected. ' 'The representation, thus, requires a definite description style resolution for the $x$ that is characterized as a fourth lucky number (with respect to the given setting, $x$ together with its description will be accomodated at the main level I)RS), and it presupposes a reference event $c^{\prime}$ such that the sentence cvent $e$ is the first event of a possible elaboration sequence of $e^{\prime}$ (cf. (Hbe92) for the computation and storing of disconrse rela-

\footnotetext{
${ }^{1}$ As regards definite descriptions, the distinguished DRF is the DRF of the head noun; in any case it is the DRF the ex-information is contered aromed.

Modeltheoretically the relation between the presuppositional part and the assertional part of a DRS can be seen as a function from information states into information states, sec (Kam95).
}

tions like elaboration).

\subsection{The lixclusion of Preceding Altcrnatives interpretation}

In the EPA-reading, erst is used as a focus adverb, i.e. it structures its argument into focus and background. In the following representation of (1), we consider the case where the numeral is focused only, not the NP containing the numeral or the entire event description in the scope of erst:

(1.b)

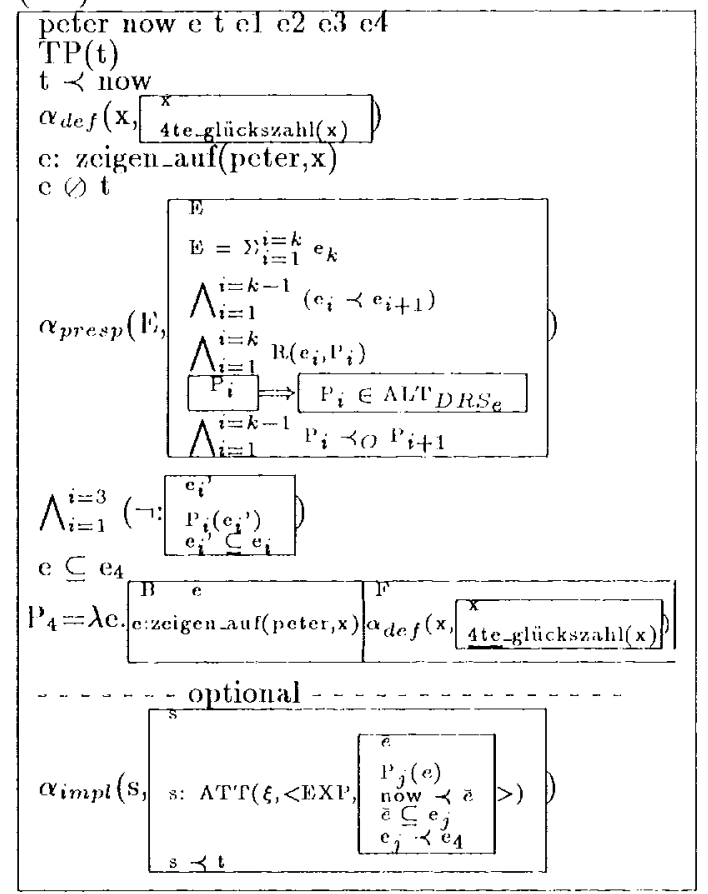

Besides the assertion that Peter points to the fourth lucky number at the temporal perspective $t$, the representation presipposes a sum li con sisting of a sequence of events $c_{1}-c_{k}$ that are related via a non further specified relation $R$ to predicates $P_{1}-P_{k}$. These $P_{i}$ are required to be alternatives of the event description in the scope of erst (which is called $\lambda$ e. J)RS $S_{e}$ ). In this paper, we cannot go into detail with the computation of the alternatives of event descriptions. $\mathrm{P}_{i} \in A \mathrm{~L}^{\prime} \mathrm{I}^{\prime} D R S_{0}$, where $\Lambda \mathrm{LT}_{D R S_{\mathrm{e}}}=\left\{\lambda e . D R S_{e\left[P O G_{e l}\left(D R S_{e}\right) \mid Q\right]} \mid Q \in\right.$ $\left.A I T\left(I^{\prime} O C_{e l}\left(D R S_{e}\right)\right)\right\}$, sketchos the claim that the $P_{i}$ are event descriptions that develop from $\lambda$ c.I.)RS $S_{e}$ by exchanging the focused element by an alternative (Compare (Roo85), (Roo92) for the underlying focus theory and (BE95) for an algorithm that calculates the concrete alterna tives). As mentioned, the focused element, which is marked by the underline, is assumed to be the numeral adjective. This choico triggers the structuring of the Ps into the background event type $\lambda e . B A C\left(D R S_{e}\right.$ ) (which is $\lambda$ c. [eeigen-auf(peter, $x)$ and the focused scmantic constituent $\lambda x, V^{\prime} O C\left(D R S_{e}\right)_{[4 \mid n]}$ (which is 
$\lambda \mathrm{x} . \alpha_{\text {def }}\left(\mathrm{x},\left[\begin{array}{l}\mathrm{x} \\ \text { nte_glückszahl }(\mathrm{x})\end{array}\right]\right.$, where $\mathrm{n}$ is a number from the set of alternatives of 4 ). The relation $R$ has to be understood as characterizing the $e_{i}$ as opportunities for Peter to point to (specific) numbers. In (1), these opportunities may be situations that can be described by: The first $_{e_{1}} /$ second $_{e_{2}} /$ third $_{e_{3}}$ number is presented to Peter. The order of the oppertunities is inherited from the order of the Ps, $\prec_{0}$, which conforms to the intrinsic order of the set of alternatives of the focused element (i.e. $\left.\mathrm{O}=\operatorname{order}\left(A L T\left(F O C_{e l}\left(D R S_{e}\right)\right)\right)\right)$. In (1), this is the canonical order of the numbers.

The negation test, which is commonly used to detect presuppositions, supports these structural assumptions.

Now, we think that the EPA-reading interpretes the asserted cvent, which is backed by the described scenario, as the first one that is indeed realized within the range of possible instantiations that the sequence of opportunities provides, i.e. the asserted event presents the first positive outcome to the test about the instantiation of the de. $B A C\left(D R S_{\varepsilon}\right)$-type that is connected to the $\mathrm{e}_{i}$ sequence, where each test situation $e_{i}$ is characterized by its own specific additional test criterion $\lambda x . F O C\left(D R S_{e}\right)_{[1 \mid n]}{ }^{2}$

Further linguistic tests, that we must omit here, support the assumption that the information about the negative tests is an entailment. Therefore, in the representation, the negated DRSs for the pointing-opportunities $e_{1}-e_{3}$ are part of the main DRS.

In the literature the representation of the focusing use of erst (and corresponding uses of noch and schon) often comprises the information that the reported realization of the event is earlicr or later (depending on the reading and the adverb) than the speaker/writer and/or the recipient (or even a third person) would have expected. We think that such an expectation, in the case of the EPA-reading of erst, is only optional. Following (Kön91), we think that, if present, it is not a presupposition but a conventional implicaturc. In (1.b), we use the specific $\alpha_{i m p l}$-format and the representation convention of (Kam95) for attitudinal states in order to express the EPA-expectation of a previous test to be successful.

\subsection{The Retardation interpretation}

As for the EPA-reading, we consider the case where the numeral is focussed only:

\footnotetext{
${ }^{2}$ Depending on the focus structure of the phrase in the scope of erst in (1) and depending on the contextual restrictions of the admissible alternatives, other sets of Ps might result. It is clear that depending on this choice, the focus conditions may characterize a thematic role, as in the described example, or the event variable. It is also clear, as we will argue in the next section, that not all of these sets of alternatives can accept the EPA-reading.
}

(1.c)

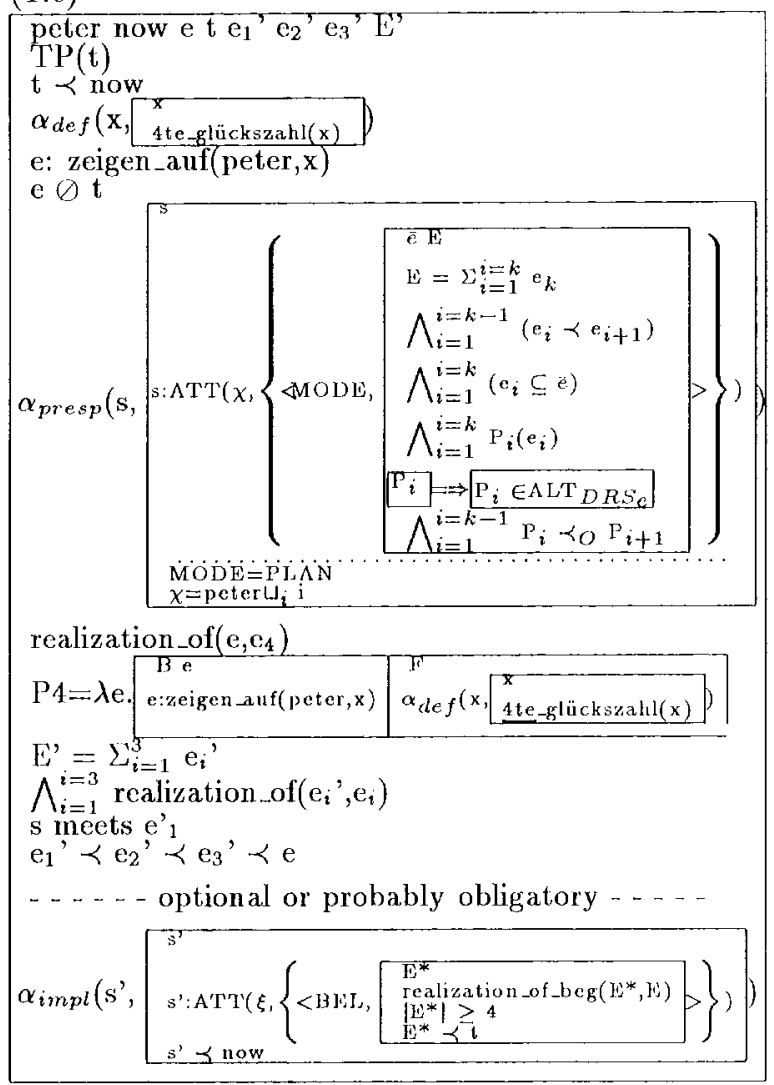

In contrast to the EPA-reading, we assume that, in the $\mathrm{R}$-reading, the predicates $\mathrm{P}_{i}$ that we obtain from the information structure of the erstargument are not related to a sequence of opportunities for doing something, but describe events $\mathrm{e}_{2}$ of an expectation about the ongoing of the world $\bar{e}$ or a plan $\bar{e}$. 'The context (1) doesn't provide further information about the identity of the person or persons $\chi$ to whom the introcluced attitudiual state has to be ascribed, to the speaker/writer, to the recipient, to Peter, to someone clse or to some group of salient people. Also it doesn't provide information about the nature of the attitude $\mathrm{MOI}$ ). The conditions that are introduced below the dotted line exemplify possible resolutions. According to this, Peter and the speaker/writer (i for tho distinguished DRF for the self) share the attitude of having a plan for realizing $\ddot{e}$. Such resolutions may be available by an inference component that operates over richer contextual knowledge. Again. the order of the $\mathbf{P}_{i}$ and the corresponding $e_{i}$ is inferred from the implicit order of the alternatives of the focused element. From this setting and the assertion of an occurrence of Peter poinling to the fourlh lucky number at the temporal perspective $t$, the representation entails realizations of those events of the presupposition line that precede the counterpart of $e$ in the presupposed sequence. As a further (possibly optional) constraint, the R-reading introduces the implicature that a non further specified person or grouj $\xi \mathrm{cx}$ - 
pected for the perspective time that the planned or expected sequence of eventis should be realized to a greater degree. Without further information about the identity of $\xi$, it is difficult to say something more precise about the temporal location of the $\xi$-expectation than that an instance s' of the corresponding attitudinal static holds al some time before the actual now.

\section{Disambiguating Criteria}

\subsection{Tho Syntax Criterion}

In German focus adverbs cannot be topicalized as such, i.e. they cannot occur in the vorfeld position without an accompanying constituent ( $\mathrm{cf}$. (Kön9l)). If the sentence shows such a topicalization of erst - which is ratarked by the inversion of the basic Subj-Vlin-order - erst can only be used as a time adverb, i.e. its meaning can only be the l'S-reading, as exemplified by (2):

(2) Lrst gab Peter Maria den Brief'.

(First, Peter handed the letter to Maria.)

Thus, this type of topicalization disambiguates between the F'S-reading on the one hand and the El'A-and R-reading on the other. Whether there are other syntactic criteria that further disam. bignate betwoen the threo readings also depends on the structural description assigned to the focus particle use. There are suggestions of analysing focus adverbs as syntactic co-constituents of their foci, and there are suggestions for analysing them only as co-constituents of the verb or its projections (soe (13ay85), (13ay88), (Jac89), (Jac84), (Kön91) among others for a discussion). We have nothing specific to say about this here. Wo just note that, wuder the common assumption that the vorfeld in German introduces at most one (onstituent and under the ensuing assumption that focus adverbs modify their foci, in sentences like (3), erst must be interpreted as focus adverb.

(3) Lirst den Briel gab Poter Maria.

(l'eter only handed the letter to Maria.)

As concerns the l'S-roading, we add that, provided it is syntactically licensed, this reading is strongly supported if the sentence $\$ 2$ following the erstsentence $\$ 1$ contains an adverb of temporal succesion (like dann/then, danach/afler this etc.) that modifies a verbal projection of similar tense and information steucture as the erst-argmment. 'This latter heuristics is expensive however, in that it checks extra-sentential information. 'The following crileria avoid this.

\subsection{The Focus-Backgromed Criterion}

If the assumption of section 2.2 is true that in the l'PA-secenario the background event type is tested for specific realizations, it is natural to think of this scenario to be reasonably conceptinalized only if the background event type merits testing. This is not the case if there is no background event type at all (i.e. Ae. $\left.B A C(I) R S_{e}\right)$ is the most general event predicate). 'There is no background event type if the entire argument of erst - the vorb or a verbal projection - is in focus, or, though not in focus, the verb does not carry enough substance in order to provide an event type: this is the case for the copula without the predicative complement. Instead of technically working out the criterion, we content ourselves with some motivating exarnples which are critical in this respect. In order to avoid interfering effects from the syntactic: structure that might complicate matters with regard to determine the scope of erst, we only list exampless with verb final position. In (4), the parentheses mark the argument of erst, the brackets anmotated by $l$ ' the focus element from which the semantic focus constituent is developed. As an example, (4.a) and (4.b) present their resulting structured event types. Wo omit this rather canonical structuring for the other exarnples.

(4) Petra war überrascht, weil (Petra was surprised because)

a) Peter crst (in [Stuttgart $]_{r^{\prime}}$ war)

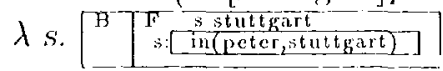
$*\left(L^{\prime} A\right)$

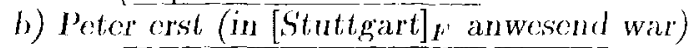

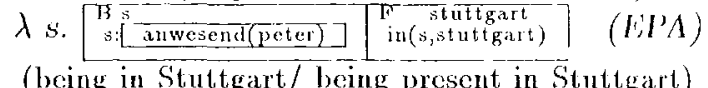
(being in Stultgart/ being present in Stuttgart)
es erst ( $[12.00]_{F}$ war)

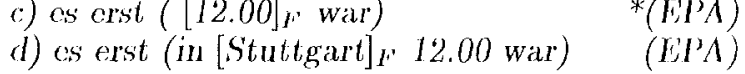
(being 12 o'clock / being 12 o'clock in Stuttgart) c) Peter crst ([arbeitete $]_{F^{\prime}}$ ) *(KPA)

f) Peter erst (in [Stutigart] ${ }_{1}$ arbeitete) (LPA) (working in Stuttgart)

The indications (WPA) and * (WPA) mean that one can conceive contexts that allow for liph or that onc ean not. Without further comment, we think that the criterion is confirmed by the data.

l'ocus-l3ackground-criterion:

The FPA-reacling is aceptable only if the scope of erst is structured into locus and background in such a way that the background is a specific event type.

\subsection{Tho Temporal location Criterion}

The R-reading presupposes a sequence of events (conceptualized as a plan or an expectation aboul. the ongoing of the world) and it assumes that, from the perspective of the contextual perspecelive time, a part of the sequence is realized, according to the ordering of the plan or expectation. 'The reported event refers to the event of the jresupposition line that marks the boundary between the instiantiated and the nou-instantiated event con. copts, and it does this in right the samo way as definite descriptions do with respect to their antecedents. Now, if this is tue and if the eventi description contains a temporal location in the focus; this information cannot be used at, tribu tively, because it, contributes to the antecedent de- 
scription and to the distinction of this antecedent from its alternatives. Because of this setting, it acts as a restriction on the referring expression that helps to pick up the right antecedent from the presupposition line. 'This means that, against the background of the presupposition, this information is not new. We add that nothing of the erst-argument is new information against this background. New is the information about the progress of the instantiation of the presupposed cvent concepts. But then, stating that an event of the corresponding antecedent type indeed was realized (the assertional impact of the $\mathrm{R}$-reading), and stating that it occurred at a time as was expected (consequence of the specific description of 'antecedent' and 'anaphor'), and simultaneously insinuating that it could have been realized earlier (presuppasitional structure of the R-reading supported by implicature) results in a contradiction. This, to our opinion, seems to be the explanation of why the $R$-reading is not possible in case the description in the scope of erst comes with a temporal location in the focus. Compare the following examples to this end.

(5) Petra war überrascht, weil

a) Peter erst (in [Stuttgart $]_{F}$ war)

b) Peter erst (um $[12.00]_{F}$ in Stuttgart war)*(R)

(5) confirms what we have said so far. Note, by the way, that the features of the Focus-Backgroundcriterion arc not characteristic of the R-reading.

What about temporal locations in the background part? $\Lambda \mathbf{t}$ first glance, it seems that what we have said above applies to this case also. However, there are some (relatively marginal) cases that possibly contradict to this assumption. The following example (6) is an instance of this:

(6) ... weil Peter erst (in [München $]_{F}$ um 3 ein Bier getrunken hat)

(because only in Munich, Peter drank a beer at three (so far))

In a context that continues this information, for instance, by und noch nicht in Köln (am nächsten Tag) um 3 / and not yet in Cologne (the next day) at 3 the $R$-reading seems acceptable. Because of the granularity of the presuppositional event sequence that develops from the presupposition construction in such cases - in (6), the iteration must satisfy to a one-day-rhythm at least- the temporal adjunct cannot truly act as a restrictive referential constraint, and because of what we have said above about novelty, it is not the best attributive information also. This may explain why the example is felt to be a bit odd. The decisive feature, however, why the above argumentation for the incompatibility of the R-reading and the presence of temporal localizations does not go through, is the fact that the background temporal localization does not uniquely fix the occurrence time of the event with regard to the time frame of the presupposed plan or expectation. This, of course, is so, only if the localizing predicate allows for multiple (periodic) instantiation. ('Times of day allow for this, also adjuncts like after lunch ctc.).

We stress that what we have said relates to temporal adjuncts in the scope of erst. 'The following (7.a) allows for the R-reading, because the most natural analysis gives wide scope to the temporal adjunct, i.e. the sentence is analysed like (7.b), where clearly, the adjunct serves to localize the temporal perspective.

(7) a) Erst in München war or gestern.

b) wcil er gestern erst in München war. (yesterday being in Munich)

We have considered only temporal adjuncts so far. The alternative temporal localization that occurs in the scope of erst is the construction 'copula + predicative temporal expression', which accepts the R-reading. Examples are (4.c) and (4.d). We skip the complete explanatory argument here and just say that (grosso modo) the function of the copula construction is to synchronize calendar knowledge (also information about different calendars: R-reading of (4.d)) with the actual available perspective times, whereas the function of the temporal adjunct is to relate the described event to some predefined time. We take it for granted, that this difference is the reason why the decisive conflict that we mentioned further above only arises if the temporal location is introduced by modification, i.e. in case it is introduced by an adjunct.

We retain the following criterion:

Temporal-Location-criterion:

The R-reading is acceptable only if the focus constituent of the scope of erst does not contribute a temporal localization (by modification of a basic event type). In addition, the scope inust not contain an adjunct - focused or not - that is a uniquely referring temporal location (like yesterday).

\subsection{The Entailment Criterion}

Compare the following examples:

(8) ... weil

a) Tomba sich erst (an der [Streifalmhütte $]_{r}$ disqualifizierte).

(T. disqualified himself at the $S.) \quad *(R),(E P A)$

b) erst ( $[\text { drei }]_{F}$, Unterschriften genügten).

(three signatures were sufficient.) * $(R),(E P A)$

c) Peter erst ( [vier $]_{F}$ Angestellte kannte).

(P. knew four employees.)

$(R),{ }^{*}(E P A)$

(8.a) cannot have the R-reading. Why? The intelligent construction of the presuppositional sequence of events for the R-reading outputs a number of disqualification events that are located at particular places of the IIahnenkamm downhill race in Kitzbühel. What is specific with this sequence is the fact that the postconditions of any of these events are such that the preconditions of the successive events never can hold. Therefore such a sequence can never be a reasonable plan ol' 
a reasonable expectation about a downhill race. I.c. a constitutive element of the R-reading cannot be constructed in this case. In (8.b) the descriptions of subsequent events (states in this caso) of the presuppositional line are more general predicates than the description of the predecessors, i.c. each such sequence collapses in its first clement in essence. This cannot truly be called a sequence. With (8.c), we encounter, so to speak, the symmetric picture with regard to the lil'A-reading: Knowing $n$ employees cntails the previously tested knowing $n-1$ cmployecs. 'The expectation of some proposition $p$ to be true in a specific situation $s_{n}$ cannot be falsified, in case the validity of a particular proposition o in the subsequent test situation $s_{n+1}$ confirms the validity of $p$.

We retain the following criterion:

Entailment-criterion:

For the R-reading to be aceeptable, first, the postconditions of cach event of the presuppositional line rumst be compatible with the preconditions of the successor and second, (at least for homogeneous descriptions) the description of an event must not subsume the description of the following cenentis.

for the WPA-roading to be acceptable, (at last for homogenoous descriptions) the event description tested at a sibuation must not subsume the previously tested event description.

'There are refinements of this criterion that we must omit, here.

\section{Final Remarks}

'The four criteria of the last section can be used in order to exclude readings of ersl. It is only the last (cntailment) criterion that necessitates some conomic semantic inferencing. 'The others correspond more or less to a structural lookup. Using the convincing structural interdependencies that (Lob89) shows for a subset of the German focus adverbs containing erst, the generalization of the approach suggested here to other ambiguous adverbs secms very promising.

\section{References}

J. Bayer. Adjazenz und Kettenbildung. Bemerkungen zur Syntax der dentschen (iradpartikclı, 1985. (ıns.) Max-I'lanck-Instibut für Psycholinguistik.

J. Bayer. Rightward movement and the syulax of quantificational particles in German. In V. Rosen, editor, l'apers from the Tenth Scandinavian Conference of Linguistics 1 , Bergen, Norway, 1988.

Peter I. Blok and Kurt liherle. What is the alternative. In Peter Bosch and Rob van der Sandt, editors, F'ocus and Nalural Language Processing, Procedings of the Interdisciplinary Con- ference in Celebration of the 10th Anniversary of the Journal of Semantics. IBM, IIeidelborg, 1995.

J. Bos, l.Mastenbroek, S.McGlastian, S.Millies, and M.Pinkal. 'The Verbmobil semantic formalism. VM report 6, Universitat des Saarlandes, 1994.

Kurt Wberle. On representing the temporal structure of a natural language text. In Procedings of Coling 92, Nantes, $199^{\circ}$.

Kurt Pberle. Ku eincr Semantik für Dialogverste. hen und Übersetzung. Verbunobil-Repost 8:3, Universitaet Stuttgart, 1995.

Jakob Hoepelman and (hhristian Rohrer. Remarks on noch and schon in (ierman. Syntax and Semantics, 14:103-126, 1981.

J. Jacolss. 'The syntax of bound focus in German Groninger Arbeiten zur Germanistischen linguistik, 25:172 - 200, 1984 .

J. Jacobs. Fokus und Skalen. Zur Synlax und S'mantik der (iradpartikeln im l)eulschen. Nicmeyer, 'lïibingen, 1989.

IIans Kamp. A theory of truth and semantic representation. In J.A.G. Groenendijk, 'I'.M.V. Janssen, and M.B.J. Stokhof, editors, formal Methods in the Study of Language. Mathemat. ical ('entre Tract, Amsterdam, 1981.

Hans Kamp. Some elements of a I)RT-based theory of the represcutation of mental states and verbal commmnication. (ms.), IMS, Universitäi Stuttgart, 1995.

rkkehard König. $\Lambda$ semantic analysis of Cerman 'erst'. In Rainer Bäucele, U. Fgli, and Aminr von Stechow, cditors, Semantics from Differcnl Points of View, pages 148 - 160. Springer, Berlin, Heidelberg, New York, 'Tokyo, 1979.

Fkkchard Konig. The Meaning of l'ocus Particles: A Comparalive Perspective. Routledise, London, New York, 1991.

Stephen (. Levinson. Pragmatics. Cambriclgo University P'ress, Cambridge, Now York, 1983.

Sobastian Iöbner. Schon - erst -noch: An integrated analysis. In Werner $\Lambda$ braham, editor, Discourse Parlicles, pages 85 - 140. Niemcycr, 'Liibingen, 1989.

Mats Li. Rooth. Association with focus. Phl) thesis, University of Massachusetts at, $\Lambda$ mherst, 1985.

Mats F. Rooth. A theory of focus interpretation. Natural Language Semantics, 1(1):75117,1992 .

Rob van der Sandt. Presupposition projection as anaphora resolution. Journal of Semantics, $9(4), 1992$ 